\title{
EL COMPORTAMIENTO LECTOR EN TEXTOS MULTIMODALES DIGITALES EN LA BÁSICA PRIMARIA
}

Calle-Álvarez, Gerzon Yair; Gómez-Sierra, Malca Irina

EL COMPORTAMIENTO LECTOR EN TEXTOS MULTIMODALES DIGITALES EN LA BÁSICA PRIMARIA PANORAMA, vol. 14, núm. 27, 2020

Politécnico Grancolombiano, Colombia

Disponible en: http://www.redalyc.org/articulo.oa?id=343964051002

DOI: https://doi.org/10.15765/pnrm.v14i27.1518

https://journal.poligran.edu.co/index.php/panorama/about/submissions\#copyrightNotice

Esta obra está bajo una Licencia Creative Commons Atribución-NoComercial-SinDerivar 4.0 Internacional. 
Artículos de investigación científica y tecnológica

\title{
EL COMPORTAMIENTO LECTOR EN TEXTOS MULTIMODALES DIGITALES EN LA BÁSICA PRIMARIA
}

\author{
READING BEHAVIOUR IN DIGITAL MULTIMODAL \\ TEXTS IN PRIMARY SCHOOL \\ COMPORTAMENTO DE LEITURA EM TEXTOS \\ MULTIMODAIS DIGITAIS NA ESCOLA PRIMÁRIA \\ Gerzon Yair Calle-Álvarez gerzon.calle@udea.edu.co \\ Universidad de Antioquia., Colombia \\ Malca Irina Gómez-Sierra malca.gomez@udea.edu.co \\ Universidad de Antioquia., Colombia
}

PANORAMA, vol. 14, núm. 27, 2020

Politécnico Grancolombiano, Colombia

Recepción: 26 Julio 2019

Aprobación: 05 Junio 2020

DOI: https://doi.org/10.15765/ pnrm.v14i27.1518

Redalyc: http://www.redalyc.org/ articulo.oa?id $=343964051002$

https://journal.poligran.edu.co/ index.php/panorama/about/ submissions\# copyrightNotice CC BY-NC-ND
Resumen: La lectura en diferentes soportes permite identificar habilidades e intereses de un lector, evidenciadas en sus actitudes, en su capacidad de análisis e interacción social, desarrollándose conductas que inciden significativamente en la adquisición del comportamiento lector, y posibilita establecer factores relevantes que influyen en el comportamiento lector de los estudiantes de grado tercero de básica primaria. En este documento se utilizó un enfoque cualitativo, método investigación-acción, mediante entrevista a 20 estudiantes de tercer grado, en el municipio de Yondó, Antioquia, de una institución pública. Se destacan los factores de hábito lector, tipos de textos, multimodalidad y trabajo en equipo, así como procedimientos durante la lectura en medio electrónico de los estudiantes revisados para este estudio. Se concluye que la escuela sigue siendo un actor fundamental para lograr que los estudiantes se interesen por la lectura y favorezcan su comportamiento lector.

Palabras clave: Educación básica, comportamiento lector, textos multimodales.

Abstract: Reading in different media allows to identify skills and interests of a reader, evidenced in their attitudes, in their capacity of analysis and social interaction; developing behaviors that significantly affect the acquisition of reading behavior. To establish relevant factors that influence the reading behavior of third grade elementary students. Qualitative approach, research-action method, by interviewing 20 third grade students in the municipality of Yondó, Antioquia, from a public institution. The factors of reading habits, types of texts, multimodality and teamwork, as well as procedures during electronic reading of the students reviewed for this study are highlighted. The school continues to be a fundamental actor in getting students interested in reading and in favoring their reading behavior.

Keywords: Basic education, reader behavior, multimodal texts.

Resumo: A leitura em diferentes meios permite identificar as capacidades e interesses de um leitor, evidenciados nas suas atitudes, na sua capacidade de análise e interacção social; desenvolvendo comportamentos que afectam significativamente a aquisição de comportamento de leitura. Estabelecer factores relevantes que influenciam o comportamento de leitura dos alunos do terceiro ano do ensino básico. Abordagem qualitativa, método de investigação-acção, entrevistando 20 estudantes do terceiro ano do município de Yondó, Antioquia, de uma instituição pública. Os factores de hábitos de leitura, tipos de textos, multimodalidade e trabalho de equipa, bem como os procedimentos durante a leitura electrónica dos alunos analisados para este estudo são 
destacados. A escola continua a ser um actor fundamental para conseguir que os alunos se interessem pela leitura e para favorecer o seu comportamento de leitura.

Palavras-chave: Educação básica, comportamento de leitura, textos multimodais.

\section{INTRODUCCIÓN}

La lectura ha tenido diversas concepciones en cuanto a su práctica en los diferentes contextos sociales en que se desenvuelve el ser humano, siendo abordada más allá de la codificación textual como una práctica cultural donde se evidencian comportamientos y actitudes del sujeto, y como portadora de significado para el lector (Chartier \& Bourdieu, 2010). Por su parte, Cassany (2006), habla sobre la necesidad de avanzar a un nivel sociocultural donde las prácticas comunicativas y la interacción tengan sentido en el contexto social, adquiriendo un carácter pragmático, evidenciándose las distintas maneras de enfrentarse a la lectura que están realizando los nuevos lectores.

Alpuche y Vega (2014), indican que la autoeficacia en la lectura predice el comportamiento lector en niños de primer grado. Para dicha investigación plantean que la interacción entre el contexto y sus capacidades le permitirá alcanzar desempeños académicos significativos. Para tal efecto aplicaron el instrumento de observación de los logros de la lectoescritura inicial y la escala de autoeficacia en la lectura, propuestas por los autores, concluyendo que generar a los estudiantes confianza en sus habilidades -partiendo de sus conocimientos básicos- promueve prácticas lectoras exitosas.

La Organización de Estados Iberoamericanos, OEI, (2006), en su informe sobre políticas de promoción de la lectura y la escritura, estableció que la lectura ha tenido un incremento notable en algunos países y que factores como el placer, la actualización de conocimientos y la exigencia académica son las principales razones por las que se lee. De igual manera, Yubero y Larrañaga (2010) exponen en su investigación que la niñez es quien más lee, sin embargo, no todos lo hacen por interés o en tiempo de ocio; indican que la lectura debe partir del interés del estudiante, apoyado en que debe hacer parte de un estilo de vida, en el cual su contexto social -en especial su familia- son parte fundamental para la adquisición de hábitos, ya que son ellos los principales motivadores de la lectura y en quienes los niños ven reflejados comportamientos lectores, entendiendo estos como las expresiones que se dan entre el lector y texto, evidenciándose en sus intereses, actitudes, disposición frente a la lectura, sentimientos, donde el sujeto es partícipe del contexto social.

Mujica, Guido y Gutiérrez (2012), en su investigación con estudiantes mexicanos entre los 14 y 20 años, evidencian la existencia de factores motivacionales que inciden en el comportamiento lector, como son la influencia familiar, el nivel académico y social. Aclaran que el acompañamiento familiar y el grado académico de los padres son fundamentales en las actividades lectoras de sus hijos en cada uno de los estratos sociales. Así mismo, Mujica et al. (2012), indican que "en la medida que se incite el comportamiento lector en los estudiantes de 
manera propicia, se incrementará esta actividad" (p.29). Por lo anterior, se exhorta a la motivación lectora desde todos los espacios sociales, especialmente en la escuela, siendo este el lugar de encuentro, no solo como espacio académico y de conocimiento, sino como lugar para la interacción, el diálogo y el fortalecimiento de habilidades comunicativas.

A esto se suma que en la actualidad la lectura en soportes digitales está cobrando cada vez mayor fuerza (Cassany \& Ayala, 2008), lo que poco a poco está incrementando la lectura en los diferentes ambientes sociales, pues a partir de las herramientas tecnológicas los niños y jóvenes han encontrado diversas formas de leer con el fin de informarse, de conocer e interactuar, convirtiéndose en un reto para docentes a la hora de plantear actividades que busquen tal fin. A su vez plantea Cassany (2009), no desconocer en las actividades de aula el uso de las prácticas letradas vernáculas, las cuales son una oportunidad para acercar al estudiante a la lectura y conseguir aprendizajes más profundos y vivenciales, que día a día se integran a los soportes digitales.

Cordón (2010), afirma que el uso de los soportes digitales para la lectura de literatura va en aumento, lo que indica que los estudiantes no solo buscan información a partir de textos impresos, sino que tratan de complementar su información o saberes con medios digitales de modo preciso y ágil, es decir, con menor exigencia mecánica para poder centrarse en procesos cognitivos. Así mismo, establecen tiempos de lectura, con medios tecnológicos prácticos y motivantes en sus procesos lectores (Daza-Orozco, 2018). Con lo anterior no se está justificando el facilismo o la pereza frente a la lectura analógica, sino que la sociedad actual busca desde las diversas opciones que el contexto le ofrece mejores maneras de interactuar con la lectura.

En este sentido, se abre las puertas a las tecnologías de la información y la comunicación, TIC, convirtiéndose en un camino a nuevas experiencias y aprendizajes, estableciendo diversos espacios de lectura en donde la imagen, el color, el movimiento hacen motivante esta práctica, contribuyendo a que el estudiante encuentre sentido a lo que lee. De la misma manera, le permite complementar desde diversos aspectos la lectura analógica y la lectura multimodal digital.

No se desconoce la importancia que tiene la lectura de textos analógicos, sin embargo, es necesaria la inclusión de soportes digitales que involucren procesos lectores, teniendo en cuenta que las nuevas generaciones nacieron en ambientes tecnológicos y dependen de ellos en gran medida. Por lo tanto, considerarlas partícipes en los procesos lectores se convierte en un aspecto motivante para su aprendizaje en un contexto más próximo a sus intereses, donde se promueve además la participación, el análisis y el conocimiento (CERLALC-UNESCO, 2014). Lo anterior permite analizar su incidencia en el comportamiento lector de los estudiantes logrando, además, un acercamiento a sus intereses a través de los medios tecnológicos.

Aspectos como la imagen y el movimiento generan otras formas de lectura, promoviendo su desarrollo personal, académico y el contacto con otros sistemas simbólicos en su quehacer educativo. Leer implica 
un acercamiento social, en el cual el sujeto conversa con su entorno, se apropia de su saber, de sus experiencias y juega con su imaginación, comprendiendo que leer va más allá de la decodificación. Por lo tanto, es necesario reconfigurar las ideas o conceptos que han generado la apatía constante entre el lector y los diversos textos que revelan realidades e imaginarios.

La lectura está determinada por una serie de factores que inciden en el gusto, el placer o la apatía por esta, marcando el rumbo de lecturas que difieren de las diversas actividades que realiza el sujeto en la interacción con su entorno. En este sentido, se define su comportamiento lector, marcado por circunstancias positivas o negativas que repercuten significativamente en sus experiencias lectoras. Por lo anterior, se abordan conceptos desde los cuales se logra analizar y discernir de algunas prácticas y experiencias lectoras que inciden notablemente en el quehacer escolar y social de las personas. El presente artículo tiene como propósito presentar los resultados de una investigación que tenía en sus objetivos establecer los factores relevantes que influyen en el comportamiento lector de los estudiantes de tercer grado de básica primaria.

\section{MÉTODO}

La educación va de la mano con los cambios de estructuras sociales que repercuten significativamente en el quehacer de los maestros, siendo esto una manera de adquirir compromisos y brindar posibles respuestas a las necesidades y problemáticas educativas que día a día trascienden en las prácticas pedagógicas, lo que genera en el maestro una actitud reflexiva y crítica ante una realidad cada vez más compleja, vinculándolo a ser partícipe de experiencias e investigaciones que contribuyan notablemente a cambios personales, educativos y sociales -como se plantea en esta investigación-.

En el presente estudio se asumió una investigación de carácter cualitativo, expresado a partir del planteamiento del problema en el cual se busca analizar la incidencia de los textos multimodales digitales en el comportamiento lector de los estudiantes de tercer grado; igualmente, conocer aspectos relevantes que influyen en dicho estudio mediante la implementación de una propuesta didáctica crítica.

Para Hernández, Fernández y Baptista (2010), “el enfoque cualitativo puede concebirse como un conjunto de prácticas interpretativas que hacen al mundo "visible", lo transforman y convierten en una serie de representaciones en forma de observaciones, anotaciones, grabaciones y documentos" (p.10). De esta manera, el investigador y sus participantes interactúan constantemente, por lo que es viable conocer e interpretar experiencias y situaciones de su entorno, siempre respetuosos de sus pensamientos u opiniones. En este sentido, se buscó en la presente investigación, desde el ambiente escolar, realizar un estudio del comportamiento lector, la lectura multimodal digital y la didáctica crítica, pretendiendo dar una mirada global. Como lo plantean Hernández et al. (2010), la investigación cualitativa "proporciona profundidad a los 
datos, dispersión, riqueza interpretativa, contextualización del ambiente o entorno, detalles y experiencias únicas" (p.17). Por lo tanto, se logra que la investigación sea confiable, dinámica, flexible tanto en el uso de las técnicas, en su recolección como en el análisis de información.

Los estudiantes de tercer grado son el eje central, quienes, a partir de sus experiencias, opiniones y posturas, permitieron describir, comprender e interpretar los sucesos e informaciones relacionadas con el comportamiento lector asociado a la lectura de textos multimodales digitales, así como aspectos relevantes que se relacionaron con dicho objeto de estudio.

Para la presente investigación se determinó implementar la investigación-acción como método que permite sistematizar la praxis educativa, así como establecer los momentos o fases estratégicas de planificación, ejecución, observación, reflexión y evaluación. Es una herramienta cualitativa donde el investigador logra alcanzar sus objetivos previamente establecidos, por medio de un trabajo cíclico (Carr \& Kemmis, 1988), organizado sobre dos ejes: uno estratégico, constituido por la acción y la reflexión; y otro organizativo, constituido por la planificación y la observación. Esto con el propósito de comprender e interpretar las situaciones evidenciadas en el aula de clases y cómo contribuir a establecer acciones de mejora.

De acuerdo con lo planteado por Carr y Kemmis (1988), se exponen las fases desarrolladas:

- La planificación: en esta primera fase se tomó una idea o problemática a mejorar; se realizó inicialmente un diagnóstico de las situaciones que reflejó, además, las posturas de los sujetos involucrados y, de esta manera, planificar una estrategia.

- La acción: en esta segunda fase se ejecutó el plan de acción el cual tuvo un carácter flexible, en tanto permitió ajustes de acuerdo con una reflexión basada en la revisión y análisis de datos e información obtenida previamente.

- La observación: como siguiente fase se hizo una supervisión y análisis de lo que allí se evidenció. Para realizar una observación acertada fue necesario utilizar instrumentos que aportaron información suficiente y válida para la acción emprendida.

- La reflexión: esta última fase tuvo por objetivo analizar e interpretar la información obtenida. Para esto se requirió reducir la información al punto de codificar todo aquello que guardó sentido para la investigación, validar la información, hacerla creíble.

Para el desarrollo de la investigación se abordó un periodo escolar, en el cual se ejecutaron tres ciclos constituidos cada uno por un tipo de texto: narrativo, expositivo y argumentativo, donde se emplearon los textos multimodales digitales como herramienta que orientó dicho proyecto. Terminado los ciclos se realizó un informe final que expresó de manera detallada los procesos ejecutados, develando los resultados que de allí se obtuvieron teniendo en cuenta los imprevistos, los ajustes y las acciones desarrolladas. En consecuencia, resultó una investigación sólida que evidenció un proyecto de equipo, en el cual el investigador se convirtió 
en un sujeto activo, autocrítico, ajustándose a un contexto determinado, contribuyendo a mejorar prácticas educativas y sociales.

Para la muestra utilizada para este ejercicio se consultaron 31 estudiantes distribuidos en 18 hombres y 13 mujeres de los cursos analizados. La población analizada perteneciente a los estratos sociales 0 y 1 , presentaba unos rangos de edad que oscilaba entre los 7 y los 12 años de edad. El instrumento se aplicó en las asignaturas de Ciencias sociales, Informática, Ética y Lengua castellana en diferentes sesiones de trabajo.

Los estudiantes de la Institución Educativa Luis Eduardo Díaz se sorprendieron con las historias en los soportes digitales, la imagen, los cómics, todo aquello que les generaba inquietud creativa. Sus descansos estaban acompañados de tabletas y descargas de historias en celulares. Es por ello que solicitaron a sus docentes que cambiaran sus rutinas académicas, que se diera mayor uso a las herramientas digitales que tienen en su institución, creando nuevos espacios de interacción.

En la propuesta didáctica crítica planteada en la presente investigación se diseñó un blog, donde las producciones digitales y actividades propuestas por el maestro y los estudiantes fueron publicadas. Los trabajos que se publicaron en el blog fueron decididos por los estudiantes, pues algunos consideraron sentirse inseguros de mostrar sus producciones. Se evidenció la participación de algunos padres de familia en las lecturas de los textos multimodales digitales, así como en los espacios de opinión registrados en los comentarios. Indicaron sentirse complacidos de poder interactuar con la escuela y de ver los avances que tuvieron sus hijos durante el desarrollo de la propuesta didáctica crítica.

Para la recolección de la información se diseñó una entrevista semipautada. La entrevista es una técnica de investigación que tuvo como objetivo entablar un diálogo ameno y de confesiones por parte del entrevistado, orientada a una temática determinada y pautas establecidas por el entrevistador. Para Hernández et al. (2014), la entrevista "permite profundizar en detalles y argumentos sobre temas que se han podido tratar más genéricamente al aplicar un cuestionario, consiguiendo así mayor calidad y fiabilidad en la información obtenida" (p.11). De acuerdo con esto, el orden de las preguntas pudo variar conforme las respuestas otorgadas por el entrevistado, así como ser incluidas otras que previamente no estaban. Como ventaja, la entrevista brindó la posibilidad de estar cara a cara con el entrevistado y analizar además sus posturas físicas (gestos, movimientos corporales), y el silencio como una manifestación de duda, inconformidad, temor, etc. (Callejo, 2002). En el presente estudio los entrevistados fueron los estudiantes de tercer grado, quienes previas instrucciones tuvieron la oportunidad de opinar y valorar aspectos evidenciados en la investigación.

Para su validación fue necesario contar con la revisión de dos expertos, quienes realizaron observaciones. Uno de los revisores indicó que el instrumento fue pertinente conforme a las actividades y situaciones que los estudiantes podrían manifestar acorde con su edad. Otro revisor solicitó replantear una de las preguntas para generar mayor comprensión por parte de los niños. Así mismo, se contó con la implementación de este 
en un aula con características similares a la población real para su posterior aplicación. Para la ejecución de dicha entrevista se pidió a los participantes respondieran libremente, desde sus experiencias e intereses. Esta se realizó de manera individual en un único momento, y como tiempo límite se estableció una hora.

Como se mencionó anteriormente, la entrevista semipautada fue realizada por uno de los investigadores al finalizar cada ciclo con un grupo aproximado de siete estudiantes, es decir, en tres momentos del desarrollo de la secuencia didáctica crítica. Dicha entrevista permitió identificar aspectos que incidieron en el comportamiento lector en textos multimodales digitales en los estudiantes de tercer grado. Los nombres de los estudiantes fueron sustituidos por números de 1 al 20, de acuerdo con el orden de las entrevistas realizadas. Para la digitalización no se descartó ninguna respuesta, considerando que todo lo expresado fuese válido para el análisis.

El análisis se realizó de manera inductiva, buscando respetar las respuestas de los estudiantes. Se resaltaron frases o expresiones que se relacionaran con conceptos que se abordaron desde la investigación. Para el análisis se trabajó con 20 entrevistas, teniendo en cuenta que su implementación se hizo con estudiantes que tuvieran disposición para participar.

\section{RESULTADOS}

A continuación se presenta el análisis realizado a las entrevistas semipautadas aplicadas a los estudiantes de tercer grado. Su propósito fue indagar sobre aspectos relacionados con las experiencias lectoras de los estudiantes, sus usos, ambientes, el contexto en el que se desenvuelven y cómo las TIC hicieron parte de estas prácticas; de igual modo, analizar cómo inciden los textos multimodales en el comportamiento lector de los estudiantes de tercer grado. Las entrevistas se realizaron al finalizar cada ciclo desarrollado en la secuencia didáctica crítica. Es decir, se desarrollaron tres sesiones de entrevista. La guía de entrevista implementada constó de 15 preguntas abiertas. Para el análisis se tuvieron en cuenta las respuestas dadas, las cuales arrojaron una serie de subcategorías que conversan con los objetivos propuestos en la investigación.

\section{Factor 1: hábito lector}

En el análisis de las entrevistas realizadas a los estudiantes, desde la primera sesión hasta la última, consideran la lectura como una práctica basada en el placer, en el interés por conocer qué hay detrás de cada texto leído (Daza-Orozco, 2019). De allí que al preguntarles iqué momentos del día escogiste para leer?, los estudiantes han establecido en su mayoría los fines de semana u horarios contrarios a la jornada escolar. El estudiante 1 indica: "momentos como en la tardecita, cuando estoy desocupada o en la 
mañana cuando me vengo para la escuela o cuando llegue de la escuela". El estudiante 2 afirma: "los dias libres, porque abi no me toca hacer tareas ni nada y me queda el día libre. Porque el viernes yo puedo hacer la tarea y el día me queda libre, los dos dias me quedan libres y yo puedo leer y no me toca nada que hacer". Aunque en sus respuestas no hay una conexión directa con los horarios o espacios de lectura que se dan en la escuela, estos podrían ser la base para sus búsquedas personales e interacciones con sus semejantes, ya que tampoco se evidencia un rechazo por las lecturas que se hacen dentro del aula de clase.

En la segunda y tercera sesión de entrevistas, algunos estudiantes expresaron utilizar los soportes digitales para leer. El estudiante 15 expresa: "todas las mañanas, lunes, martes y los domingos que no nos dejan tarea yo busco el internet y leo". Los estudiantes han encontrado en las herramientas digitales una manera para hacer sus lecturas de acuerdo con sus propios intereses y a orientaciones dadas por la maestra, las cuales en su mayoría fueron compartidas en el aula de clase o en el edublog. De allí que la lectura toma sentido para ellos al vincularse al entorno en que se desenvuelven. El hábito lector aporta al comportamiento lector, en la medida en que se vinculan componentes como el acompañamiento familiar, el ejemplo, motivaciones e intereses y momentos de lectura establecidos en el hogar, en la escuela o por los mismos estudiantes. Se evidencia una relación lectura-contexto interesante, en tanto se reconoce al lector como un sujeto que vincula sus emociones, su sentir en su práctica lectora y que no es ajeno a su realidad.

La comunidad yondosina ha venido replanteando la importancia de la lectura, pensada esta como un espacio de interacción, diálogo y construcción de saberes, develando intereses particulares y comunes mediados por factores sociales y académicos. El contexto social es un factor determinante que hace visible el interés por leer textos en diversos soportes, donde quienes tienen un mayor estatus social gozan de un hábito lector mayor a quienes tienen un estatus social más bajo (Moya \& Gerber, 2016). Esta es una constante visible, que no es ajena al municipio de Yondó, sin embargo, se buscan estrategias encaminadas a vincular al sujeto a espacios contextuados donde la lectura sea el eje central y convoque a favorecer el comportamiento lector desde edades tempranas, formando sujetos críticos, reflexivos y autónomos.

\section{Factor 2: tipos de textos}

$\mathrm{Al}$ preguntarles a los estudiantes ¿̨cuáles son los textos digitales que más te interesa leer?, sus intereses en cuanto a la lectura multimodal digital durante el transcurso de la secuencia didáctica fueron los textos de corte narrativo, afirmando que estos son textos interesantes por sus historias, personajes, que les generan aprendizajes y diversión. Algunas expresiones de los estudiantes son: estudiante 7: "porque me enseñan y me gustan los personajes. Porque no son los mismos del cuento del libro." Estudiante 13: "porque me gustan y me hacen reir a veces". Los estudiantes se sienten atraídos por la ficción que hay en estos textos, los cuales les permiten 
desarrollar la imaginación quizá con mayor facilidad que otros tipos de textos. En ese sentido, Camps (2005), afirma que "el cuento permite evocar en la mente de los niños mundos de ficción a través del lenguaje, contribuye a la construcción de esquemas mentales propios de los géneros narrativos" (p.7). De allí que los textos que comparten con sus familiares y amigos tiendan a ser de este mismo corte, donde se generan espacios para dialogar o compartir experiencias llenas de magia, ilusión y relacionarlos con situaciones de su diario vivir.

En menor cantidad, algunos estudiantes se interesaron por los textos expositivos. El estudiante 11 expresa: "porque son cosas importantes, porque a mi me gusta, porque aprendo." El estudiante 14 indica: "porque muestran unos afiches muy bonitos que hay que cuidar el planeta, que hay que cuidar los rios, las lagunas, los peces, todo eso. No hay que botar mugre a las lagunas, no hay que contaminar el planeta tierra porque eso contamina el planeta tierra". En sus expresiones se establece una relación entre sus saberes y la construcción de nuevos aprendizajes a partir de la interacción con su entorno, su realidad y sus posturas en pro de un beneficio común. De igual manera, se analiza que la imagen y el color en un texto cautivan su atención, permitiendo que hagan sus propias lecturas asociadas con mayor frecuencia a sus saberes o su entorno.

Durante el ejercicio se presenta a los estudiantes textos de varias modalidades, narración, exposición y de argumento; se percibe un mayor interés en los de tipo narrativo. Camps (2002, p.34), plantea que

los materiales de lectura a los que acceden los individuos están ligados a los procesos de lectura y escritura de los círculos en los que conviven. Una de las posibles causas por la que los estudiantes retoman los textos narrativos, a pesar de que les presentan otros, tiene que ver con que en su casa o en los escenarios culturales en los que ellos se desarrollan sean estos textos los que mayor oferta tengan para que ellos lean, escriban y alcancen los niveles de comprensión lectora.

\section{Factor 3: Multimodalidad}

Para los estudiantes realizar lecturas en el computador resulta ser una experiencia interesante; esto puede darse porque la más común es la lectura analógica. Además, porque no consideraban que sus búsquedas pudiesen llegar a ser textos, así como las cortas lecturas que hacen al ingresar a redes sociales o enlaces de interés, denominadas por Cassany (2009), como prácticas letradas vernáculas. Para los estudiantes, la lectura en el computador es importante porque las búsquedas son más rápidas, existen lecturas nuevas cada día, por las imágenes y el color, porque les genera aprendizajes y practicidad. El estudiante 10 afirma: "porque leo las imágenes, leo lo interesante, porque me parece interesante, porque encuentro cosas que no sabia y lo puedo hacer solo o con mis papás". El estudiante ha comprendido que, además del código alfabético, existen otros recursos semióticos que se pueden leer, los cuales promueven saberes y cuestionamientos. Se evidencia que el acompañamiento de la familia se convierte en un factor importante en su comportamiento lector (Mujica 
et al., 2012). Como en algunos hogares a los estudiantes no les permiten salir a la biblioteca, consideran que utilizar el computador desde el hogar los puede acercar a la lectura de diversos textos de su interés. El estudiante 17 indica: "a mi me interesa mucho porque a mi no me dejan ir a la biblioteca, pero puedo leer desde la casa”. El uso de textos multimodales digitales permite que los estudiantes se vinculen a diversos tipos de textos que se ofrecen, de tal manera que vayan adquiriendo mayor sentido sobre el uso de las herramientas digitales. Ya estas son utilizadas no solo para ver juegos, sino también para hacer lecturas de textos que compartirá con su familia o compañeros cercanos.

A los estudiantes les interesa más que la docente utilice en el aula textos de corte digital, por la accesibilidad a diversos tipos de textos y temáticas, por los distintos recursos semióticos que encuentran y, según ellos, porque genera atención de su parte. Al respecto, el estudiante 10 afirma: "porque usted encuentra todo. Usted nos puede leer cualquier tipo de historias, porque se ven más hermosos los colores, porque se ven más cargados los libros. Perdón, porque no cargamos libros". De igual manera, consideran que estos tipos de textos les permiten mayor acceso a nuevos aprendizajes, los cuales pueden compartir con sus compañeros, opinar, analizar y ampliar saberes a partir de su contexto social. Estudiante 5: "porque abi hay muchas cosas para aprender como aprender a respetar". Estudiante 16: "porque puedo leer más, porque puedo aprender más". Estudiante 11: "porque a mi me gustan, porque estamos más atentos, tiene mucho color, el cuidado del agua, el cuidado de los manaties y por eso siempre tenemos que cuidar las aguas". Por expresiones como las anteriores podemos afirmar que, si bien los estudiantes se divierten con estos textos, también lograron establecer relaciones con su entorno cercano. Moreno (2002), indica que, aunque la lectura está vinculada con la escuela, considerada como el lugar donde se desarrollan hábitos lectores, la familia y el entorno social son factores que inciden en esta práctica social.

\section{Factor 4: trabajo en equipo}

Al preguntar a los estudiantes ¿cómo te has sentido al trabajar en equipo y cumplir con los roles establecidos?, se evidenció que este fue satisfactorio, reconociendo ser sujetos más propositivos, decididos y seguros de sus opiniones. Consideran que se fortaleció la confianza, el compañerismo y la solidaridad. En este sentido, el estudiante 18 afirmó: "bien, porque eso lo hacemos en equipo y nos podemos ayudar entre si mismos". El estudiante 14 expresó: "muy bien porque los compañeritos me han explicado y entonces de ahi voy aprendiendo, los que saben me van enseñando". De allí que la mayoría de los estudiantes mejoraron sus relaciones interpersonales por considerar que todos merecen el mismo trato para mejorar su convivencia; todo ello ha girado en torno a las lecturas sugeridas y a las reflexiones que han surgido de las experiencias. Solo dos estudiantes se sintieron inconformes con el trabajo desarrollado con sus compañeros. Se sintieron desmotivados porque sus compañeros no valoraron sus aportes y comentarios. 
Consideraron los estudiantes que las herramientas digitales fueron una oportunidad para expresar y leer opiniones de sus compañeros. Por medio del edublog los estudiantes dieron sus opiniones con libertad, aportaron experiencias y saberes. Igualmente, lograron vincularse algunos padres de familia, quienes de manera libre hicieron sus comentarios y aportes. El estudiante 5 afirmó "si, porque podemos leer lo que piensan los amigos, o decir lo que uno no está de acuerdo y hasta que me acompañen mis papás". La integración de áreas permitió que los estudiantes tuvieran bases para desarrollar cada una de las actividades propuestas e ingresar al blog con mayor facilidad, logrando realizar las actividades y lecturas interactivas, los comentarios y posturas críticas, y hacer lecturas de los textos multimodales diseñados por sus compañeros, tales como afiches, cómics y videos.

Todos los estudiantes utilizaron el edublog mientras se encontraban en la institución. Castillo, Pedraza y Roa (2015), afirman que la implementación del blog como estrategia de aprendizaje promueve en los estudiantes el mejoramiento de la lectura, al generar relaciones comprensivas entre la imagen, el video y el texto, favoreciendo el trabajo en equipo y realizando lectura mental de textos digitales y procesos de realimentación.

A continuación, se presenta un gráfico que resume los factores y aspectos relevantes de las entrevistas realizadas a los estudiantes, que conllevan a analizar el comportamiento lector mediante el uso de los textos multimodales digitales:

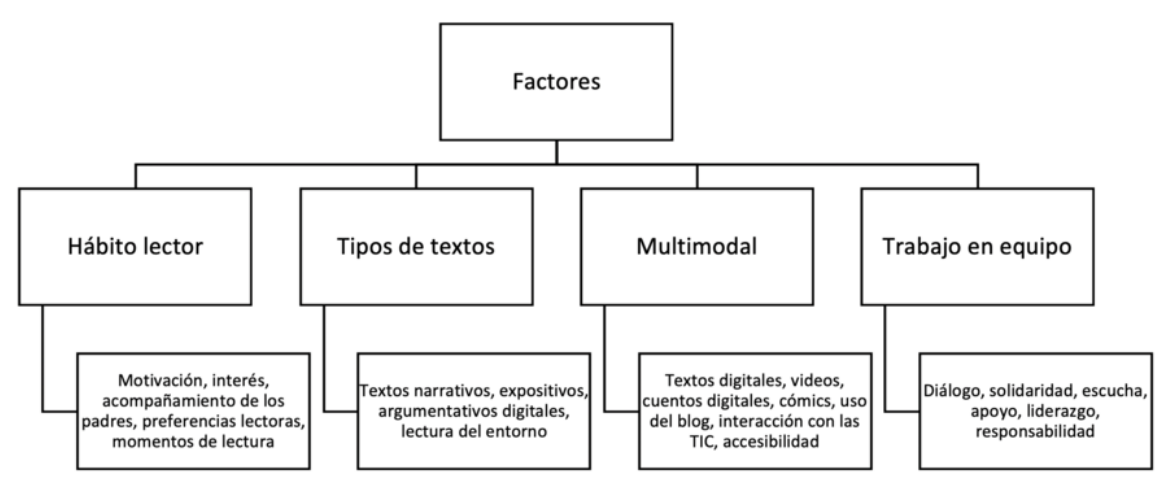

Gráfica 1.

Análisis de entrevista semi estructurada

Elaboración propia

Durante las entrevistas realizadas en cada una de las sesiones de la propuesta didáctica, se evidenció en los estudiantes el interés por los tipos de textos propuestos. Así mismo, expresaron sus gustos, especialmente por los textos narrativos, puntualmente los cuentos. Su motivación por la lectura siempre ha sido notoria, pero para algunos estudiantes sus espacios para la lectura estaban condicionados a la escuela y, en algunos momentos, a los que se brindan en sus barrios.

La entrevista permitió conocer las expectativas de los estudiantes, sus procesos lectores, espacios de lectura e intereses más allá del carácter 
académico, donde su realidad fue abordada y tenida en cuenta en cada una de las sesiones de la secuencia didáctica. Permitió, además, analizar la necesidad de implementar espacios diversos para la lectura, donde hagan parte textos multimodales digitales, considerando aún más los intereses propios de los estudiantes y cómo estos pueden ir de la mano con los aprendizajes que la escuela pretende impulsar. De allí que vincular diversas áreas académicas, situaciones de la vida cotidiana de los estudiantes y un espacio como el edublog motiven tanto la participación de los estudiantes como de sus padres o familiares cercanos y contribuyan a entablar encuentros, conocer los intereses de sus hijos e interactuar de manera significativa con las herramientas digitales. Mujica et al. (2012), en su investigación exponen que existen diversos factores motivacionales que influyen significativamente en el comportamiento lector de los estudiantes, e indican que la familia es quien con su ejemplo y acompañamiento promueve en sus hijos el interés por leer. Sin embargo, este acompañamiento va de la mano con el nivel socioeconómico donde, a su vez, el nivel educativo reprime la motivación lectora.

Si bien los textos impresos resultan importantes en el proceso lector de los estudiantes, los textos multimodales digitales promueven que los estudiantes exploren los diversos recursos semióticos que este le ofrece, haciendo sus propias lecturas y/o complementando lecturas previamente realizadas, favoreciendo su análisis y comprensión frente a las mismas. Para los estudiantes, leer textos multimodales digitales les ha permitido tener nuevas maneras de acceder a la lectura, y más aún cuando no pueden desplazarse a las bibliotecas; tener motivos para dialogar y debatir con sus compañeros aspectos relacionados con estos textos y establecer hipótesis de sus comprensiones.

\section{DISCUSIÓN}

Las entrevistas permitieron evidenciar en los estudiantes un interés constante por tener un encuentro con los textos multimodales digitales, por descubrir qué iban a encontrar al momento de iniciar sus lecturas y cómo el edublog logró establecer nuevas relaciones con sus compañeros y padres de familia al tener un espacio en común donde interactuar, compartir nuevas lecturas y comentarios que serían de interés para muchos de ellos. Afirma Orihuela (2006), que los blogs "aumentan el interés de los estudiantes en el aprendizaje y abren cauces efectivos de participación que facilitan el diálogo y el discurso académico" (p.170). Lo anterior se vio reflejado en cada una de las actividades planteadas y hasta el momento siguen siendo una opción significativa para dar sentido a los aprendizajes adquiridos.

Por sus respuestas, en la lectura de textos multimodales digitales los estudiantes se interesaron con mayor frecuencia en las imágenes de los textos, lo cual les permitió discriminar espacios, colores, expresiones y movimientos que allí se encontraban. Afirma Chacón (2015), que "la experiencia de lectura de imágenes en los primeros años escolares demanda del lector complejas habilidades visuales e intelectuales que el 
niño es capaz de completar" (p.5). De ahí que al preguntarles en algunas ocasiones por sus textos leídos mencionaban aspectos puntuales de este; aún si se les preguntaba el título de la historia algunos de ellos respondían con el nombre de un personaje o un lugar.

El comportamiento lector de los estudiantes se hace visible en su interés por la lectura de los textos, en sus preferencias, en el aumento de sus horarios de lectura dentro y fuera de la institución sin la imposición del docente. Los estudiantes solicitaban espacios para interactuar con herramientas tecnológicas para hacer sus lecturas y socializar sus puntos de vista. De allí que los niveles lectores fueron cada vez más altos. En este sentido, se requiere de una lectura que implique un acercamiento al contexto del estudiante, que le permita reconocer en sus lecturas situaciones de su entorno encaminándolo a decisiones y posturas cada vez más acordes con su edad (Cassany, 2009).

La lectura en soportes digitales se convirtió en una oportunidad de interactuar con otros tipos de textos. Sin entrar a cuestionar el uso de textos impresos, la lectura digital se vinculó de manera significativa en los procesos lectores de los estudiantes, reconociendo que ellos tienen cada vez mayor acceso a las herramientas tecnológicas. A esto afirma Cassany (2011), "la lectura digital es una práctica corriente hoy en día para muchos alumnos y lo será más en el futuro, a medida que crezca el acceso a la red con móviles, portátiles y pantallas públicas" (p.31). Su uso permitió develar los intereses, actitudes del lector frente a lo que este le expresaba, de tal manera que los códigos no verbales también se convirtieron en un aspecto importante para interpretar y dejar ver las opiniones que dichas lecturas le generaron.

Los estudiantes se interesaron por leer los textos propuestos y, a su vez, realizar búsquedas de las temáticas propuestas de tal manera que pudiesen tener bases para opinar y proponer situaciones y experiencias a sus compañeros. En sus búsquedas, los textos multimodales que sobresalieron fueron los cuentos digitales, los cuales fueron presentados a sus compañeros de manera oral o mediante el edublog. Estos intereses se dan según los estudiantes por su carácter fantástico y divertido, donde la magia, el color y los personajes les inspiran a seguirlos y a establecer cierta relación con sucesos de su cotidianidad.

Frente al factor contexto social se reconoce la relación del sujeto con su entorno como factor que incide en la construcción de nuevos saberes, nuevos aprendizajes. De ahí que el estudiante se sintiera cómodo en su interacción con los textos, lográndose establecer espacios de participación, concertación y cuestionamientos que, posteriormente, le permitieron ser un sujeto propositivo y crítico. Duarte (2012), indica que el comportamiento lector es evidente en un sujeto cuando este se apropia del significado del texto, lo comprende y está en la capacidad de establecer un diálogo efectivo con otros interlocutores, demostrando su capacidad de análisis, autonomía y criticidad.

La presencia de los textos multimodales digitales planteó nuevos retos a fin de preparar a los estudiantes para que fuesen capaces de acceder a su comprensión y de configurar la lectura como una práctica 
fundamental para el desarrollo del pensamiento, como vía para el acceso a la información y la adquisición de conocimientos en torno a su realidad social, aun cuando esta lectura desde un formato digital dejó evidenciar otras maneras de interacción con su realidad. Esto implica, además, adquirir posturas críticas que giran alrededor de su entorno social que permite al sujeto pensar, opinar, decidir e involucrarse en aquellas situaciones que le competen, aportando desde su saber y su ser propuestas que favorezcan su crecimiento personal e intelectual. CERLALC-UNESCO (2014), expone que el comportamiento lector se manifiesta por medio de las distintas prácticas lectoras, comprendidas desde las diferentes representaciones y formatos utilizados por el lector. Dicha manifestación va de la mano con sus actos, intereses o propósitos, gustos, motivaciones y significados propios, mediados por el contexto sociocultural en que se desenvuelve, del cual se desprenden competencias propias de la lectura que emergen e inciden en el comportamiento lector.

La incursión de las nuevas herramientas tecnológicas en la vida de los niños y jóvenes está siendo determinante para que la escuela como institución empiece a tomar conciencia de su implementación en las distintas actividades y prácticas pedagógicas que allí se desarrollen. Su uso estimula la experimentación, la reflexión, así como el aprendizaje colaborativo (Coll, Mauri y Onrubia, 2011). Promueve el fortalecimiento de habilidades comunicativas, saberes y la participación activa de los individuos. De allí la importancia que se aborden aspectos que realmente incidan en el aprendizaje de los estudiantes, donde el tiempo que se dedique y el objetivo a cumplir sean consecuentes con las necesidades e intereses de los estudiantes y a la vez con el currículo institucional.

El factor multimodalidad se hizo visible en todo momento, siendo que los textos tenían implícito el uso de diversos recursos semióticos. La implementación de videos, textos digitales, cómics, afiches se constituyó en un medio significativo para los estudiantes en cuanto a la lectura. Propició entornos de aprendizaje significativos, de interacción, logrando la participación activa. Así mismo, permitió espacios de comunicación, de posturas que se relacionaron con situaciones de la realidad social que les afectan a los estudiantes. “...estos entornos posibilitan nuevos modos de leer y de escribir y nuevas prácticas de lectura y de escritura, y que exigen del lector $-\mathrm{y}$ del escritor- nuevos conocimientos, habilidades y competencias" (Coll, 2005, p.8).

Se evidenció interés por parte de los estudiantes en el diseño y lectura de textos multimodales digitales, facilitó ejemplificar, expresar y defender sus comentarios y argumentos ante sus compañeros y posibles lectores. Motivó el ingreso frecuente a las actividades, realizándolas las veces que deseaban para poder entablar discusiones con sus compañeros. Los estudiantes encontraron en las herramientas digitales una manera de interactuar con textos que, si bien fortalecen procesos lectores, han incidido en su comportamiento lector: intereses por algún tipo de texto, espacios y tiempos de lectura, una manera de interactuar con textos cuando carecen de los impresos o no les es posible asistir a una biblioteca como expresaron algunos estudiantes, favoreciéndoles a nivel intelectual y 
personal. La implementación de textos multimodales digitales favorecen procesos de pensamiento, en los cuales ponen a prueba sus habilidades para interpretar, inferir y construir significado (Calle, 2014).

El trabajo en equipo se hizo visible desde las primeras sesiones. En la primera sesión se establecieron pautas de convivencia que motivaron llevar buenas relaciones en el aula. Conformar los equipos de trabajo permitió asignar roles que favorecieron en los estudiantes la seguridad, la responsabilidad y el liderazgo. De igual manera, el respeto por el otro fortaleció la escucha activa de manera significativa, ya que anterior a la aplicación de la propuesta era difícil mantener atentos a los estudiantes cuando sus compañeros expresaban sus opiniones o experiencias.

Las experiencias personales y presaberes que emergen a partir de los textos propuestos incidieron en que los estudiantes tuvieran mayor conciencia sobre temáticas sociales que los involucraban, como fueron el cuidado del medio ambiente, el respeto por su cuerpo y por el otro, al punto que varias de las actividades desarrolladas fueron multiplicadas por ellos a estudiantes de otras aulas de clase. Hubo dos estudiantes que se sintieron incómodos participando en equipo, ya que percibieron que sus compañeros no les tomaron en cuenta y no valoraban sus opiniones. Esta situación se dialogó y se establecieron acuerdos para minimizar esta situación en el aula.

Trabajar en equipo permitió que se crearan pequeños equipos de lectura, quienes compartían sus experiencias lectoras en horas de descanso o antes de ingresar al aula. En estos horarios comentaban qué habían leído, qué les había interesado y qué no, proponían textos para leer o búsquedas de textos para su próximo encuentro. Algunos estudiantes se sentían impedidos de participar en estos equipos por indicar que carecían de internet o una herramienta tecnológica. Esta situación motivó a la docente a tomar tiempo del día viernes para que hicieran búsquedas de textos, leyeran y los compartieran con sus compañeros.

\section{CONCLUSIONES}

La lectura ha sido y seguirá siendo un tema de investigación, en tanto se cuente con una problemática y una población determinada. En esta oportunidad, el comportamiento lector se convirtió más que en una problemática en una situación motivante para indagar. Lo anterior por estar en un entorno multicultural, donde los intereses son diversos, y en esta oportunidad la lectura se convierte en un espacio de interacción y diversión. Para los estudiantes de tercer grado de la Institución Educativa Luis Eduardo Díaz, la lectura se convierte en un espacio de placer, donde libremente leen, imaginan, dialogan y discuten alrededor de un tema interesante. Alpuche y Vega (2014), plantean que los estudiantes son sujetos activos, y bajo ambientes de aprendizaje contextuados, sus experiencias y capacidades pueden alcanzar niveles de lectura que favorezcan su comportamiento lector.

El comportamiento lector en la básica primaria permite exponer conceptos, factores motivacionales, fortalezas y debilidades en cuanto 
a un contexto determinado, del cual la escuela y la familia no pueden escapar. Se pudo concluir que si bien la familia, por sus hábitos lectores, ocupaciones o por ser iletrados se les dificulta acercar a sus hijos al gusto por la lectura, el entorno brinda espacios para que el estudiante se enamore de ella: la biblioteca y la escuela. La institución educativa tiene la responsabilidad de acercar a los niños a la lectura, facilitar espacios de encuentro, donde sea el estudiante quien en sus primeros años reconozca sus gustos y así acompañarlo a conocer otros tipos de textos. Posteriormente tendrá la oportunidad de ser un sujeto autónomo, reflexivo y crítico frente a lo que lee. La escuela debe tener presente los planteamientos que establecen las políticas estatales en cuanto a los procesos de lectura y cómo estos inciden en el comportamiento lector de los estudiantes e implementar sus programas. Se evidenció que los estudiantes tienen un estilo propio de lectura, de ahí su nivel de atención, memoria y uso de los sentidos. Así mismo, sus tiempos de lectura varían de acuerdo con el interés que demuestran por ciertos tipos de textos. Cabe mencionar las prácticas vernáculas que realizan los estudiantes, esto se convierte en un aspecto relevante en sus prácticas lectoras, pues hablan de sus gustos y espacios y tiempos de lectura. De allí que se reconozca que la lectura también se da en soportes digitales.

En la actualidad, el sujeto tiene cada vez mayor acceso a la tecnología y aprovecha para interactuar con sitios web, páginas, juegos y diversos tipos de información. Esto permite acercarlo a espacios lectores que incidan en su comportamiento lector. Desde los primeros años se familiarizan con diversos tipos de textos, de tal manera que será él quien decida sus gustos. Un número mayor de estudiantes indicaron sentirse más interesados por leer textos multimodales digitales, porque centraban su atención con las imágenes que se presentaban, el color o los movimientos que se dan. Cordón (2010), sostiene que la implementación de soportes digitales motiva significativamente el hábito lector y, por ende, favorece el comportamiento lector.

Implementar la lectura de textos multimodales digitales implica más que un cambio a las prácticas de lectura; es una aproximación significativa a una forma de dar sentido a lo que los estudiantes leen y comprenden por medio de una interacción social que lleve a la búsqueda de otras formas de desarrollar habilidades, en donde sus conocimientos y experiencias no estarán sujetas a la cotidianidad con la que se ha venido formando a la sociedad (Gutiérrez, 2008). No se puede pretender ser ajenos a los cambios tecnológicos y prácticas sociales que emergen con las interacciones de los sujetos. Urge la necesidad de estar a la vanguardia, de conocer intereses y necesidades de los estudiantes, aún más con el auge de la tecnología y los cambios sociales que movilizan en información y experiencias y que motivan la adquisición de saberes y prácticas sociales.

Es necesario considerar el contexto social del estudiante como un elemento fundamental en sus prácticas e intereses lectores. El contexto yondosino es multicultural. De ahí las diferentes formas en que se expresan, se relacionan y viven las personas. Lo anterior se refleja además en el nivel educativo, sus intereses y hábitos lectores, lo cual afecta el 
comportamiento lector de los estudiantes. Existen estudiantes con mayor dominio del código escrito; otros con mayor nivel visual, por ello su interés por la imagen, el color, el movimiento; otros estudiantes son más auditivos, de allí su interés por los audiolibros o porque le sean leídos los textos para su comprensión. Sin embargo, todos apuntan al interés por la lectura.

La lectura es reconocida como una práctica indispensable en el entorno social. Y para lograrlo se requiere alcanzar ciertos niveles de competencia, los cuales con frecuencia no se logran debido a factores que repercuten significativamente en dichas prácticas lectoras. Investigaciones realizadas por Moreno (2002), Yubero y Larrañaga (2010), Duarte (2012), Mújica et al. (2012) y Palacios-Almendro (2015), demuestran que factores como la familia, la escuela, el hábito, el soporte y modos de lectura, el trabajo en equipo, motivan o disipan el comportamiento lector. Entre otros aspectos, cabe mencionar el acompañamiento lector, el ejemplo, los encuentros lectores, facilitar distintos materiales de lectura, asistencia a biblioteca o espacios de lectura. Ante esto, la escuela es un actor fundamental para lograr que los estudiantes se interesen por la lectura y favorezcan su comportamiento lector.

\section{REFERENCIAS}

Alpuche, A., \& Vega, L. (2014). Predicción del comportamiento lector a partir de la autoeficacia. Revista mexicana de investigación educativa, 19(60), 241-266. Recuperado de: http://www.scielo.org.mx/pdf/rmie/v19n60/v 19n60a11.pdf

Calle, G. (2014). La habilidad del pensamiento crítico para el establecimiento de una posición frente a un tema en la escritura digital. Zona Próxima, (21), 17-32. Recuperado de: http://www.scielo.org.co/pdf/zop/n21/n21a03.p df

Callejo, J. (2002). Observación, entrevista y grupo de discusión: el silencio de tres prácticas de investigación. Revista Española de Salud Pública, 76(5), 409-422. Recuperado de: http://scielo.isciii.es/scielo.php?pid=S1135-57 $272002000500004 \&$ script $=$ sci_arttext\&tlng $=\mathrm{e}$

Camps, A. (2002). Hablar en clase, aprender lengua. Aula de Innovación Educativa, (111), 6-10. Recuperado de: https://www.academia.edu/2595 0188/Hablar_en_clase_aprender_lengua

Carr, W., \& Kemmis, S. (1988). Teoría crítica de la enseñanza. La investigaciónacción en la formación del profesorado. Barcelona: Martínez Roca.

Cassany, D. (2006). Tras las líneas. Sobre la lectura contemporánea. Barcelona: Anagrama. Recuperado de: https://media.utp.edu.co/referencias-bibliograficas/uploads/referenc ias/libro/295-tras-las-lneaspdf-WB5V4-articulo.pdf

Cassany, D. (2009). Para ser letrados. Voces y miradas sobre la lectura. Barcelona: Paidós Ibérica. Recuperado de: http://media.utp.edu.co/referencias-bibliograficas/uploads/referenci as/capitulo/300-miradas-y-propuestas-sobre-la-lecturapdf-n4Q87-libro. $\mathrm{pdf}$ 
Cassany, D., \& Ayala, G. (2008). Nativos e inmigrantes digitales en la escuela. CEE Participación Educativa, (9), 53-71. Recuperado de: http://www.iessierrasur.es/fileadmin/template/archivos/BiologiaGe ologia/documentos/DEP_DE_FORMACION/Nativos_e_inmigrantes _digitales.pdf

Cassany, D. (2011). Prácticas lectoras democratizadoras. Textos de didáctica de la lengua y la literatura, (58), 29-40. Recuperado de: https://repositori.up f.edu/bitstream/handle/10230/24635/cassany_textos58_prac.pdf?seq

Castillo, T., Pedraza, M., \& Roa, J. (2015). La estrategia Bliv-blog de lectura, imagen y video-para el desarrollo de habilidades en lectura en grado cuarto de primaria del Colegio Saludcoop Sur de Bogotá. Trabajo de grado, Universidad de la Salle, Bogotá. Recuperado de: http://repository.lasalle.edu.co/bitstream/handle/10185/18437/260 92038_2015.pdf? sequence $=1 \&$ is Allowed $=y$

CERLALC-UNESCO. (2014). Metodología común para explorar y medir el comportamiento lector. El encuentro con lo digital. Bogotá. Recuperado de: http://cerlalc.org/estudiosyestadisticas/2015/10/07/metodologia-co mun-para-explorar-y-medir-el-comportamiento-lector-el-encuentro-con -lo-digital-2/

Chacón, A. (2015). La multimodalidad del cómic: una experiencia de lectura de imágenes en los primeros grados escolares. Enunciación, 20(2), 10-26. Recuperado de: http://revistas.udistrital.edu.co/ojs/index.php/enunc/ar ticle/view/9728

Chartier, R. \& Bourdieu, P. (2010). La lectura como práctica cultural. En: El sentido social del gusto. Buenos Aires: Siglo XXI. Recuperado de: https:// es.scribd.com/document/56017376/Bourdieu-El-Sentido-Social-Del-G usto-10-La-Lectura-Una-Practica-Cultural-Con-Roger-Chartier

Coll, C. (2005). Lectura y alfabetismo en la sociedad de la información. UOC Papers Revista sobre la sociedad del conocimiento, (1), 1-11. Recuperado de: http://www.uoc.edu/uocpapers/dt/esp/coll.html

Coll, C., Mauri, T., \& Onrubia, J. (2011). La utilización de las tecnologías de la información y la comunicación en la educación: del diseño tecnopedagógico educación virtual. En: Coll, C., y Monerero, C. (Eds.). Psicología de la Educación Virtual. (pp. 74-103). Madrid: Morata.

Cordón, J. (2010). De la lectura ensimismada a la lectura colaborativa: nuevas topologías de la lectura en el entorno digital. Salamanca: Ediciones Universidad de Salamanca. Recuperado de: http://eprints.rclis.org/1544 1/1/lecturaensimismada.pdf

Daza-Orozco, CE.; Cera-Ochoa, R. A. (2018). Escritura con estilo: Guía práctica para publicar científicamente (1st ed.). Retrieved from http://palma.sanmateo.edu.co/index.php/catalogo/series/41-escrit ura-con-estilo-guia-practica-para-publicar-cientificamente

Daza-Orozco, CE. (2019). INICIACIÓN CIENTÍFICA Conceptualización, metodologías y buenas prácticas (1st ed.; (SCOIF), ed.). Retrieved from $\mathrm{h}$ ttp://www.scoif.com/iniciacion-cientifica/

Duarte, R. (2012). La enseñanza de la lectura y su repercusión en el desarrollo del comportamiento lector. Tesis doctoral, Universidad de Alcalá. Recuperado de: https://www.educacion.gob.es/teseo/imprimirFi cheroTesis.do?idFichero $=33248$ 
Gutiérrez, E. (2008). Leer digital: la lectura en el entorno de las nuevas tecnologías de la información y la comunicación. Signo y Pensamiento, 54(28), 144-163. Recuperado de: http://www.redalyc.org/articulo.oa?id $=86011409010$

Hernández, R., Fernández, C., \& Baptista, P. (2010). Metodología de la investigación. México: McGraw-Hill. Recuperado de: https://www.esup.edu.pe/descargas/dep_investigacion/Metodologia \%20de\%20la\%20investigaci\%C3\%B3n\%205ta\%20Edici\%C3\%B3n.pdf

Moreno, E. (2002). La familia como constitución sociocultural: su papel en la adquisición de los hábitos lectores. Portularia, (2), 309-324. Recuperado de: http://rabida.uhu.es/dspace/bitstream/handle/10272/130/b121521 6x.pdf;jsessionid=E2EC214370A6A80F491E41924BEF6ACD?sequen $\mathrm{ce}=1$

Moya, C., \& Gerber, M. (2016). La lectura en formatos digitales en el Chile actual: nuevas prácticas y viejas desigualdades. Revista Chilena de Literatura, (94), 59-77. Recuperado de: http://www.scielo.cl/pdf/rchilit e/n94/art04.pdf

Mujica, A., Guido, P., \& Gutiérrez, R. (2012). Factores emocionales y de capital cultural que inciden en el comportamiento lector en estudiantes mexicanos de nivel medio superior de diferente estrato social. Acta Colombiana de Psicología, 15(1), 21-31. Recuperado de: http://www.scielo.org.co/scielo.php?script=sci_arttext\&pid=S012391552012000100003

Organización de Estados Iberoamericanos, OEI. (2006). Políticas Educativas de Promoción de la lectura y escritura en Iberoamérica (Informe final). Madrid. Recuperado de: http://www.oei.es/historico/fomentolectura/informe_politicas_edu cativas_promocion_lectura_escritura_iberoamerica.pdf

Orihuela, J. (2006). La revolución de los blogs. España: La esfera de los libros. Recuperado de: http://dadun.unav.edu/bitstream/10171/41323/1/LaR evolucionDeLosBlogs_Orihuela_2006.pdf

Palacios-Almendro, M. (2015). Fomento del hábito lector mediante la aplicación de estrategias de animación a la lectura en primero de secundaria. Trabajo de Maestría. Universidad de Piura. Recuperado de: https://pirhua.udep.edu.pe/bitstream/handle/11042/2301/MAE_E DUC_161.pdf?sequence $=1$ \&isAllowed $=y$

Yubero, S., \& Larrañaga, E. (2010). El valor de la lectura en relación con el comportamiento lector. Un estudio sobre los hábitos lectores y el estilo de vida en niños. OCNOS, Revista de Estudios sobre Lectura, (6), 7-20. Recuperado de: https://www.revista.uclm.es/index.php/ocnos/article/vi ew/ocnos_2010.06.01/168 